\title{
The role of macroeconomic and geopolitical news on gold returns and volatility
}

\author{
Nicholas Apergis ${ }^{1} \bullet$ Tasawar Hayat ${ }^{2, *} \cdot$ Tareq Saeed $^{2}$ \\ ${ }^{1}$ University of Derby, $U K$ \\ ${ }^{2}$ King Abdulaziz University, Saudi Arabia
}

Received: 25 March 2020

Revised: 11 June 2020

Accepted: 17 June 2020

\begin{abstract}
The goal of this paper is to explore the simultaneous role of macroeconomic and geopolitical news in gold returns and its associated volatility. The analysis uses sentiment scores for certain macroeconomic and geopolitical global news, along with a GARCH modelling approach. The findings document that both types of news substantially impact gold returns and their associated volatility, with geopolitical news having a stronger impact.
\end{abstract}

Keywords: macroeconomic news; geopolitical news; gold returns; GARCHX model JEL Classification Codes: G13, G40, E70

\section{Introduction}

O'Connor et al. (2015) state that gold is linked with investors' psychology affected by news from the financial press and indicating behavioural-based inefficiency. News conveys information on shifting expectations about future gold supply and demand, which in turn impact inventory decisions and gold prices. The goal of this paper is to explore the simultaneous role of macroeconomic and geopolitical news for gold returns and their associated volatility by using a news sentiment scoring approach. Peress (2014) documents that media contributes to market efficiency by improving the dissemination of information across investors, while sentiment theories predict that rational traders highly disagree when the tone of news is positive or negative. He highlights that geopolitical news impacts gold returns, i.e. making investors disagree about future gold prices.

Tetlock (2007) shows that high pessimism predicts downward price pressures, followed by a mean reversion process to fundamentals. Our work is part of a growing strand of the literature that explores how the informational sentiment affects asset prices. Loughran and Mcdonald

\footnotetext{
*Corresponding author. E-mail: n.apergis@derby.ac.uk.

Citation: Apergis, N., Hayat, T., and Saeed, T. (2021) The role of macroeconomic and geopolitical news on gold returns and volatility, Economics and Business Letters, 10(1), 72-80.
}

DOI: $10.17811 /$ ebl.10.1.2021.72-80 
(2011) and Dougal et al. (2012) develop a finance-focused word list; they link negative sentiment to stock returns, while Soo (2013) focuses on housing-related news sentiment. In terms of the role of macroeconomic and geopolitical news factors, the literature has only paid scant attention on their role for gold prices. More specifically, in terms of macroeconomic news, Smales and Young (2015) investigate the behaviour of gold futures around the release of macroeconomic announcements, with their findings indicating that market activity, in terms of traded volumes, returns, and volatility, responds to new information relatively quickly. Baur and Smales (2018) provide further evidence that gold has a positive reaction to geopolitical risks and threats, while there is no impact in gold returns volatility due to those risks. Finally, Christie-David et al. (2000) document that gold prices do not respond to macroeconomic news releases, with similar evidence coming in terms of the associated gold price volatility. In terms of geopolitical risk factors, the work by Das et al. (2019) illustrates that certain precious metal prices, including gold prices, positively respond to geopolitical risks. Based on the above evidence, our work is substantially differentiated by considering: i) the simultaneous impact of both risk factors, ii) the findings that both factors exert an effect on both the mean gold returns and their associated volatility, which had not been explored before, except in the case of the Smyles and Young (2015) paper, iii) a broader set of news classifications, associated with sixteen macroeconomic and four geopolitical developments (with natural disasters not included before as an individual component of geopolitical risks), and iv) the employment of a new and more complete sentiment score index not considered before in the relevant literature.

\section{Data}

The analysis employs news sentiment indexes using the macro package of RavenPack News Analytics Dow Jones Edition 3.0; it obtains information on a set of news, ranging from political events, natural disasters, wars and conflicts, to the release of important macroeconomic indicators and forecasts. The sample ranges from January 1, 2000 through December 31, 2018, while the analysis converts the time of news' arrival to ET time, which is the timing convention of gold futures data released from the New York COMEX.

\subsection{Gold data}

We use closing prices of futures gold contracts traded on the NY COMEX; prices are obtained from Bloomberg and expressed in US dollars. The analysis takes the nearest-to-maturity contract with maturity month $\mathrm{T}$ and rolls to the next contract at the end of month T-2 to avoid illiquidity issues near expiration. Given that settlement prices are set as the average price of trades occurring at 13:30 ET, the analysis assumes that when a news/event occurs before 13:30, investors trade at the settlement price on the same day; if news is released after 13:30, traders trade on the next day of the settlement price. News released over weekends/holidays is treated as information on the next working day (i.e., Monday) before 13:30. Gold futures prices are transformed into gold returns by taking the percentage logarithms differences of two consecutive gold futures prices.

\subsection{News classification}

Data are classified as event driven (i.e., the breakout of a war), economic data releases, and opinions/comments. Opinions and comments appear in the media, which may emphasize the importance of specific information. The analysis uses 20 news classifications, categorized as macroeconomic (16) and geopolitical news (4) (Table 1), with an increase in all geopolitical and macroeconomic components indicating weakening geopolitical and macroeconomic risks. 
Table 1. News Classification.

\section{Geopolitical news}

Terrorism, war \& conflicts, civil unrest, natural disasters

\section{Macroeconomic news}

sovereign debt, retail sales, consumer confidence, credit ratings, foreign exchange, housing, interest rates, treasury yields, private credit, employment, consumer spending, recession, durable goods, economic growth, CPI, trade balance deficit

\subsection{News sentiment indices}

The overall macroeconomic and geopolitical news scores, as well as their individual components range from -50 (most negative sentiment) to 50 (most positive sentiment), with zero as a neutral score. For each category, it calculates an aggregate daily news index. If there are several news reports on the same day in the same category, it averages these scores across this news. The analysis standardizes these scores to work with zero mean and unit standard deviation regressors. For any news record matched with an event category, the process generates an Event Sentiment Score (ESS), while it assigns each news a relevance score. In this procedure, RavenPack News Analytics marks every macroeconomic and geopolitical news event in news items from various sources with the sentiment value of ESS. The calculation of the news-impact score series is based on the method introduced by Yu and Mitra (2016). This sentiment value quantifies the sentiment of a particular news event for the chosen entity. Depending on weekday and time, each news item is mapped to its relevant trading day. Weekend news are shifted to Monday and any news coming in after market closing time is shifted to the next working day. For each news item $\mathrm{N}_{\mathrm{i}}$, the procedure gives a time stamp timest which consists of the date and time of the release of the news item, timest $\left(\mathrm{N}_{\mathrm{i}}\right)=\left(\operatorname{date}\left(\mathrm{N}_{\mathrm{i}}\right)\right.$, time $\left.\left(\mathrm{N}_{\mathrm{i}}\right)\right)$, where $\mathrm{i}=1, \ldots, \mathrm{n}$ and $\mathrm{n}$ denotes the number of news items in the data set. It maps the time stamp of each news item to a trading day (TD) for that news item $\operatorname{TrD}\left(\mathrm{N}_{\mathrm{i}}\right)$, where $\operatorname{TrD}\left(\mathrm{N}_{\mathrm{i}}\right) \in\left\{\mathrm{TD}_{\mathrm{t}}\right\}, \mathrm{t}=1, \ldots, \mathrm{m}$. It holds that $\mathrm{TD}_{1} \geq \min _{\mathrm{i}}\left(\operatorname{date}\left(\mathrm{N}_{\mathrm{i}}\right)\right)$ and $\mathrm{TD}_{\mathrm{m}} \leq \max _{\mathrm{i}}\left(\operatorname{date}\left(\mathrm{N}_{\mathrm{i}}\right)\right)$ and $\mathrm{m}$ is the number of trading days in the given time interval $\left[\min _{\mathrm{i}}\left(\operatorname{date}\left(\mathrm{N}_{\mathrm{i}}\right)\right), \max _{\mathrm{i}}\left(\operatorname{date}\left(\mathrm{N}_{\mathrm{i}}\right)\right)\right]$. This process generates the different geopolitical and macroeconomic components of the overall indexes based on the relevance and sentiment values from RavenPack's database to build daily news sentiment values which are utilized as an input variable in the modelling process. Next, it builds the news time series $\mathrm{V}(\mathrm{t})$, with $\mathrm{n}$ being the number of news items and $\mathrm{t}$ with $\mathrm{t}=\operatorname{TrD}_{1}, \ldots, \operatorname{TrD}_{\mathrm{m}}$ indicating the current trading day:

$$
V_{t}=\sum_{i=1}^{n} n e w s_{\{\operatorname{Tr} D(N i)=t\}}
$$

This mean news-sentiment component series news index considers the ESS, which is delivered with each news event. The mean overall sentiment scores are calculated for each trading day, leading to a trading day mean news-sentiment series. The mean news-sentiment value time series MNEWS is calculated as:

$$
M N E W S_{t}=1 / V_{t} \sum_{j=1}^{n} \operatorname{ESS}\left(N_{j}\right) n e w S_{\{\operatorname{Tr} D(N i)=t\}}
$$

\section{Empirical analysis}

To explore the impact of both the macroeconomic and geopolitical news on gold returns and their associated volatility, the analysis considers the method of a GARCHX model that builds 
Table 2. GARCHX Estimates: The Role of Macroeconomic and Geopolitical Risks in Gold Returns.

\begin{tabular}{lr}
\hline \hline Mean equation & \\
\hline Constant & 0.038 \\
& {$[0.32]$} \\
gold returns(-1) & $0.731^{* * *}$ \\
& {$[0.00]$} \\
Macroeconomic risks & $-18.274^{* * *}$ \\
Geopolitical risks & {$[0.00]$} \\
& $-19.361^{* * *}$ \\
Wald F-test & {$[0.00]$} \\
\hline Conditional volatility equation & {$[0.18]$} \\
\hline Constant & \\
& $0.0032^{*}$ \\
h(-1) & {$[0.10]$} \\
& $0.509^{* * *}$ \\
$\eta^{2}(-1)$ & {$[0.00]$} \\
& $0.318^{* * *}$ \\
Macroeconomic risks & {$[0.00]$} \\
& $-1.995^{* *}$ \\
Geopolitical risks & {$[0.03]$} \\
& $-2.079^{* * *}$ \\
Wald F-test & {$[0.00]$} \\
Diagnostics & {$[0.25]$} \\
Log-likelihood & \\
LM test for Heteroscedasticity & $3,614.8$ \\
\hline Notes: Figures in brackets denote p-values. & {$[0.69]$} \\
\hline
\end{tabular}

upon the GARCH framework. We allow both types of news to enter both the mean and the conditional volatility equations of the model. The GARCHX model is based on the multivariate Factor-GARCH model by Engle et al. (1990). More specifically, an ARMA(p, q) returns process may be used to calculate errors. That is, for returns, $r_{i t}$, the following specification is used:

$$
r_{t}=a+\sum_{i=1}^{p} r_{t-i}+\sum_{i=1}^{q} m a_{t-i}+\varepsilon_{t}
$$

where the first sum represents the autoregressive component and the second sum the moving average component, with a and $\varepsilon$ being a constant and an error term, respectively. In the first step of the GARCHX method, we add to Equation (1) two new variables that proxy macroeconomic and geopolitical news, turning the model into the GARCHX specification:

$$
r_{t}=a+\sum_{i=1}^{p} b r_{t-i}+\sum_{i=1}^{q} c v_{t-i}+d_{1} M A C R O_{t}+d_{2} G E O_{t}+\eta_{t}
$$

Within a $\operatorname{GARCH}(1,1)$ framework, the equation of conditional volatility turns out to be:

$$
h_{t}=f+g h_{t-1}+m \eta^{2}{ }_{t-1}
$$

where $\mathrm{h}$ denotes the conditional volatility measure and $\eta$ is the residuals from (2). In the GARCHX modelling version, we add the two types of news, and Equation (3) yields:

$$
h_{t}=f+g h_{t-1}+m \eta^{2}{ }_{t-1}+k_{1} M A C R O_{t}+k_{1} G E O_{t}
$$


Table 3. GARCHX Estimates: The Role of Macroeconomic and Geopolitical Risks in Gold Returns (Excluding the Global Financial Crisis Period: February 2007-August 2009).

\begin{tabular}{lr}
\hline \hline Mean equation & \\
\hline Constant & 0.045 \\
gold returns(-1) & {$[0.26]$} \\
& $0.724^{* * *}$ \\
Macroeconomic risks & {$[0.00]$} \\
& $-10.772^{* * *}$ \\
Geopolitical risks & {$[0.00]$} \\
& $-22.153^{* * *}$ \\
Wald F-test & {$[0.00]$} \\
\hline Conditional volatility equation & {$[0.00]$} \\
\hline Constant & \\
& $0.0039^{*}$ \\
h(-1) & {$[0.09]$} \\
& $0.516^{* * *}$ \\
$\eta^{2}(-1)$ & {$[0.00]$} \\
Macroeconomic risks & $0.305^{* * *}$ \\
& {$[0.00]$} \\
Geopolitical risks & $-1.514^{* *}$ \\
& {$[0.03]$} \\
Wald F-test & $-4.006^{* * *}$ \\
Diagnostics & {$[0.00]$} \\
Log-likelihood & {$[0.00]$} \\
LM test for Heteroscedasticity & $3,725.7$ \\
\hline \hline
\end{tabular}

Notes: Figures in brackets denote p-values.

with the restriction of the stability conditions remaining similar to those in the traditional $\operatorname{GARCH}(1,1)$ model, that is $\mathrm{g}+\mathrm{m}<1$. The Akaike criterion recommends an $\operatorname{AR}(1)$ model for our stock future returns series.

The results, reported in Table 2, document that the estimated coefficients of the GARCHX model meet the required condition that $\mathrm{g}+\mathrm{m}<1$, which is a vital requirement for a mean reverting process. This sum $\mathrm{g}+\mathrm{m}$ measures volatility persistence. Therefore, we can conclude that the conditional volatilities are mean reverting for gold returns. Moreover, the estimates illustrate that all estimated coefficients in the conditional variance equation are statistically significant at the standard levels of significance. More importantly, the findings provide strong evidence that both the overall macroeconomic and geopolitical news factors exert a significant negative impact on mean gold returns, while the results of the conditional volatility equation also document that both types of news have a negative and statistically significant effect on the volatility of gold returns. Certain diagnostic tests, such as the LM test statistic, illustrate the absence of serial correlation in the residuals, implying that the GARCHX model is well specified. Finally, Wald F-tests in both the mean and the conditional variance equations clearly illustrate that the impact of both risks is similar.

Given that the findings could be influenced by the global financial crisis, the next step of the analysis excludes the crisis period by adopting the timeline of the crisis (defined by the FRB of St. Louis) and excluding the period February 2007-August 2009. The results (Table 3) document similar estimates. However, in terms of the relative impact of both risks on gold returns 
Table 4. GARCHX Estimates: The Role of Geopolitical Risk Components in Gold Returns.

\begin{tabular}{ll}
\hline \hline Mean equation & \\
\hline Constant & 0.016 \\
gold returns(-1) & {$[0.49]$} \\
& $0.671^{* * *}$ \\
Terrorism & {$[0.00]$} \\
& -0.371 \\
War \& conflicts & {$[0.28]$} \\
& $-11.175^{* * *}$ \\
Civil unrest & {$[0.00]$} \\
& -0.281 \\
Natural disasters & {$[0.34]$} \\
& $-15.438^{* * *}$ \\
Conditional volatility equation & {$[0.00]$} \\
\hline Constant & \\
& 0.0024 \\
h(-1) & {$[0.13]$} \\
$\eta^{2}(-1)$ & $0.501^{* * *}$ \\
& {$[0.00]$} \\
Terrorism & $0.305^{* * *}$ \\
& {$[0.00]$} \\
War \& conflicts & -0.193 \\
& {$[0.39]$} \\
Civil unrest & $-3.964 * * *$ \\
Natural disasters & {$[0.00]$} \\
Diagnostics & -0.084 \\
Log-likelihood & {$[0.52]$} \\
LM test for Heteroscedasticity & $-4.549^{* * *}$ \\
Notes: Figures in brackets denote p-values. & {$[0.57]$} \\
& {$[0.00]$} \\
& $3,784.2$ \\
& \\
&
\end{tabular}

and their volatility, Wald F-tests highlight that the impact of both risks is not similar this time, with the stronger one coming from the geopolitical news factor.

Finally, this part of the analysis repeats the GARCHX estimates by considering the specific components of both the macroeconomic and geopolitical news. The fresh findings are reported in Tables 4 (the geopolitical components) and 5 (the macroeconomic components). They document that in terms of geopolitical news, it is war and conflicts, as well as natural disasters that inflict on both gold returns and their volatility. In terms of macroeconomic news, the factors of sovereign debt, credit ratings, foreign exchange, interest rates, Treasury yields, employment, recession and economic growth seem to exert the strongest impact on gold returns (at 1\%), followed by the factors of consumer confidence and consumer credit (at 5\%), retail sales, housing, private credit and CPI (at 10\%).

\section{Conclusion}

News about macroeconomic fundamentals and geopolitical events affect both gold returns and their associated conditional volatility. The analysis, through a GARCHX modelling approach, 
Table 5. GARCHX Estimates: The Role of Macroeconomic Risk Components in Gold Returns.

\begin{tabular}{ll}
\hline Mean equation & \\
\hline Constant & 0.006 \\
gold returns(-1) & {$[0.64]$} \\
& $0.682^{* * *} *$ \\
Sovereign debt & {$[0.00]$} \\
& $-9.562^{* * *}$ \\
Retail sales & {$[0.00]$} \\
& $-3.516^{*}$ \\
Consumer confidence & {$[0.07]$} \\
& $-6.359^{* *}$ \\
Credit ratings & {$[0.04]$} \\
& -0.883 \\
Foreign exchange & {$[0.17]$} \\
& $-12.316^{* * *}$ \\
Housing & {$[0.00]$} \\
& $-1.894^{*}$ \\
Interest rates & {$[0.09]$} \\
& $-11.253^{* * *}$ \\
Treasury yields & {$[0.00]$} \\
& $-9.653^{* * *}$ \\
Private credit & {$[0.01]$} \\
Employment & $-1.774^{*}$ \\
Consumer credit & {$[0.09]$} \\
Recession & $-12.348^{* * *}$ \\
Durable goods & {$[0.00]$} \\
Economic growth & $-5.906^{* *}$ \\
CPI & {$[0.05]$} \\
& $-13.209^{* * *}$ \\
\hline \hline & {$[0.00]$} \\
& -0.984 \\
& {$[0.15]$} \\
& $-13.451^{* * *}$ \\
& {$[0.00]$} \\
& $-2.004^{*}$ \\
& {$[0.08]$} \\
& -1.043 \\
& {$[0.13]$} \\
\hline & \\
& \\
&
\end{tabular}

used sentiment scores and documented that both types of news had an impact on both gold returns and their volatility, with geopolitical news incurring a stronger effect when the analysis excluded the global financial crisis period. In terms of the entire period under consideration, macroeconomic news exerted an equally impact on both the means and the volatility of gold returns.

\section{Acknowledgments}

The authors need to express their gratitude to the two reviewers of this journal whose comments and suggestions enhanced the merit of this work. Special thanks also go to the Editor who gave them the chance to revise and resubmit their work. 
Table 5. GARCHX Estimates: The Role of Macroeconomic Risk Components in Gold Returns (cont.).

\begin{tabular}{|c|c|}
\hline \multicolumn{2}{|l|}{ Conditional volatility equation } \\
\hline Constant & $\begin{array}{l}0.0032^{*} \\
{[0.10]}\end{array}$ \\
\hline$h(-1)$ & $\begin{array}{l}0.509 * * * \\
{[0.00]}\end{array}$ \\
\hline$\eta^{2}(-1)$ & $\begin{array}{l}0.318^{* * * *} \\
{[0.00]}\end{array}$ \\
\hline Sovereign debt & $\begin{array}{l}-5.362 * * * \\
{[0.00]}\end{array}$ \\
\hline Retail sales & $\begin{array}{l}-1.385^{*} \\
{[0.07]}\end{array}$ \\
\hline Consumer confidence & $\begin{array}{l}-1.859 * * \\
{[0.05]}\end{array}$ \\
\hline Credit rating & $\begin{array}{l}-0.415 \\
{[0.18]}\end{array}$ \\
\hline Foreign exchange & $\begin{array}{l}-4.996^{* * *} \\
{[0.01]}\end{array}$ \\
\hline Housing & $\begin{array}{l}-1.539^{*} \\
{[0.06]}\end{array}$ \\
\hline Interest rates & $\begin{array}{l}-5.984 * * * \\
{[0.00]}\end{array}$ \\
\hline Treasury yields & $\begin{array}{l}-5.602 * * * \\
{[0.00]}\end{array}$ \\
\hline Private credit & $\begin{array}{l}-1.649^{*} \\
{[0.06]}\end{array}$ \\
\hline Employment & $\begin{array}{l}-6.893 * * * \\
{[0.00]}\end{array}$ \\
\hline Consumer credit & $\begin{array}{l}-1.995^{* *} \\
{[0.04]}\end{array}$ \\
\hline Recession & $\begin{array}{l}-7.894 * * * \\
{[0.00]}\end{array}$ \\
\hline Durable goods & $\begin{array}{l}-1.136^{*} \\
{[0.10]}\end{array}$ \\
\hline Economic growth & $\begin{array}{l}-7.438 * * * \\
{[0.00]}\end{array}$ \\
\hline CPI & $\begin{array}{l}-1.327 * \\
{[0.09]}\end{array}$ \\
\hline Trade balance & $\begin{array}{l}-0.763 \\
{[0.24]}\end{array}$ \\
\hline Diagnostics & \\
\hline $\begin{array}{l}\text { Log-likelihood } \\
\text { LM test for Heteroscedasticity }\end{array}$ & $\begin{array}{l}3,894.1 \\
{[0.60]}\end{array}$ \\
\hline
\end{tabular}

Notes: Figures in brackets denote p-values.

\section{References}

Baur, D., and Smales, L. A. (2018) Gold and Geopolitical Risk, SSRN Working Paper, No. 3109136. 
Christie-David, R., Chaudhry, M., and Koch, T. W. (2000) Do Macroeconomic News Releases Affect Gold and Silver Prices?, Journal of Economics and Business, 52(3), 405-421.

Das, D., Kannadhasan, M., and Bhowmik, P. (2019) Geopolitical Risk and Precious Metals, Journal of Economic Research, 24(1), 49-66.

Dougal, C., Engelberg, J., Garcia, D., and Parsons, C. (2012) Journalists and the Stock Markets, The Review of Financial Studies, 25(3), 639-679.

Engle, R. (2004) Risk and Volatility: Econometric Models and Financial Practice, American Economic Review, 94(2), 405-420.

Loughran, T., and Mcdonald, B. (2011) When is a Liability not a Liability? Textual Analysis, Dictionaries, and 10-ks, The Journal of Finance, 66(1), 35-65.

O'Connor, F. A., Lucey, B. M., Batten, J. A., and Baur, D. G. (2015) The Financial Economics of Gold-A Survey, International Review of Financial Analysis, 41(2), 186-205.

Peress, J. (2014) The Media and the Diffusion of Information in Financial Markets: Evidence from Newspaper Strikes, The Journal of Finance, 69(12), 2007-2043.

Smales, L. A., and Yang, Y. (2015) The Importance of Belief Dispersion in the Response of Gold Futures to Macroeconomic Announcements, International Review of Financial Analysis, 41(2), 292-302.

Soo, C. K. (2013) Quantifying Animal Spirits: News Media and Sentiment in the Housing Market, Working Paper, No. 1200, Michigan Ross School of Business.

Tetlock, P. C. (2007) Giving Content to Investor Sentiment: The Role of Media in the Stock Market, The Journal of Finance, 62(8), 1139-1168.

Yu, X., and Mitra, G. (2016) An Impact Measure for News: Its use in (daily) trading strategies, in: Handbook of Sentiment Analysis in Finance, edited by Mitra, G. and Yu, X., Uxbridge: OptiRisk Systems, 288-309. 